\title{
REDES SOCIAIS E BEM-ESTAR: laços sociais a a felicidade pessoal
}

Social Networks and Well-being: social ties and personal happiness

Redes sociales y bienestar: lazos sociales y la felicidad personal

Álvaro Botelho de Melo Nascimento ${ }^{1}$

\section{RESUMO}

Neste texto, é discutida a relação entre laços sociais e a construção do bem-estar. Foi demonstrado que algo singular como a busca individual pela felicidade possui aspectos densamente embebecidos de sentidos socialmente construídos. Com o auxílio da sociologia das redes sociais, nos propomos a analisar aspectos microinterativos da vida, de modo a demonstrar o cotidiano como espaço de construção de sentidos e perspectivas de bem-estar. Este texto está dividido em três tópicos além da introdução, a saber: (2) uma breve discussão sobre bem-estar subjetivo; (3) uma apresentação panorâmica sobre redes sociais e sua relação com a sociologia; e, por fim, (4) a relação entre redes sociais e bem-estar subjetivo.

PALAVRAS-CHAVE: Sociologia das Redes Sociais. Laços Sociais. Bem-estar. Felicidade.

\section{ABSTRACT}

In this text, it is discussed the relationship between social ties and the construction of well-being. It was showed that something singular like individual happiness has densely embedded aspects of socially constructed senses. With the help of the sociology of social networks, we propose to analyze micro interactional aspects of life to demonstrate daily life as a space of construction of meanings and perspectives of hapiness. The text is divided into three topics besides the introduction: (2) a brief discussion about subjective well-being; (3) a panoramic presentation about social networks and relationship with sociology; and finally, (4) the relationship between social networks and subjective well-being.

KEYWORDS: Sociology of Social Networks. Social Ties. Well-being. Happiness.

1 Mestre em Sociologia e Doutorando em Sociologia pelo Programa de Pós-graduação em Sociologia da Universidade Federal de Pernambuco. alvaro.botelho00@gmail.com. 


\section{RESUMEN}

En este texto, se discute la relación que existe entre los lazos sociales y la construcción del bienestar. Se ha demostrarado que algo singular como la búsqueda individual de la felicidad posee aspectos densamente embebidos de sentidos socialmente construidos. Con el principal apoyo de la sociología de las redes sociales, nos proponemos analizar aspectos microinternacionales de la vida, de modo que se pueda demostrar lo cotidiano como espacio de construcción de sentidos y perspectivas de bienestar. Este texto está dividido en tres temas distintos de la introducción, a saber: (2) una breve discusión sobre el bienestar subjetivo; (3) una presentación panorámica sobre las redes sociales y su relación con la sociología; y, por último, (4) la relación entre redes sociales y bienestar subjetivo.

PALABRA CLAVE: Sociología de las Redes Sociales. Lazos Sociales. Bienestar. Felicidad.

Data de submissão: 29/10/2017

Data de aceite: 19/03/2018

\section{INTRODUÇÃO}

O texto que se segue pretende abordar, sob uma ótica sociológica, o bem-estar subjetivo e sua relação com as configurações reticulares, no que toca as possibilidades e restriçóes decorrentes das redes sociais. Nas próximas linhas, é demonstrado que algo singular como a busca individual pela felicidade possui aspectos densamente embebecidos de sentidos socialmente construídos. Ao tomar como objeto desse artigo a própria felicidade como um construto social, construo uma discussão de caráter propositivo pela qual se almeja apontar a maneira como construímos nosso entendimento sobre a felicidade e como acessamos recursos para sua obtenção através de nossos arranjos reticulares e interacionais.

Partindo de referenciais interacionistas, fenomenológicos e da abordagem sociológica das redes, me proponho, portanto, a construir uma reflexão teórica sobre os aspectos microinterativos da vida de modo a demonstrar o cotidiano como espaço de construçáo de sentidos e perspectivas de bem-estar. Para tanto, primeiramente discutiremos brevemente sobre bem-estar subjetivo; logo em seguida, falaremos sobre sociologia e redes sociais; por fim, detalharemos a relação entre as configuraçóes reticulares dos atores sociais e a construção do bem-estar subjetivo no que toca ao uso e gerenciamento de capitais sociais oriundos das diversas sociabilidades que compóem nosso estar no mundo. Em suma, ao refletir sobre redes sociais e construção do bem-estar subjetivo, tentarei elucidar a íntima ligação entre laços sociais, processos de 
socializaçáo, acesso a recursos - tais como o apoio - e a felicidade individual, de tal modo a esclarecer como nosso bem-estar está imbricado com elementos interacionais e intersubjetivos, dos quais nem sempre os atores se dáo conta.

\section{BREVE DISCUSSÁO SOBRE BEM-ESTAR SUBJETIVO}

A felicidade é uma preocupação constante na reflexão humana, no entanto, o ideal de felicidade não é o mesmo daquele do início dos tempos e nem sempre foi como é na contemporaneidade. Nas palavras de MacMahon (2006, p. 14), "[...] a maneira como homens e mulheres compreendem a felicidade - como eles se propóem a conquistá-la e se têm a expectativa de fazê-la - varia drasticamente entre as culturas e ao longo do tempo. [...]"

Shott em seu artigo Emotion and Social Life: A Symbolic Interactionist Analysis (1979. p.1320) destaca que as emoções são culturalmente moldadas, que "existe um quadro social que modifica a experiência do ator, sua interpretação e expressão da emoção". Se para características tão íntimas como as emoçôes que chamamos de amor, amizade, tristeza e culpa há um filtro social ativo é possível afirmar que o mesmo ocorre com o bem-estar subjetivo. A maneira como somos e nos sentimos felizes é marcadamente social, inclusive, na contemporaneidade existem diversos projetos de bem-estar originários das mais diversas cosmovisões, as quais se intercruzam, se complementam e disputam.

A partilha de coisas tão singulares como emoçôes ou como essa espécie de "gramática do ser feliz" só é possível porque os seres humanos construíram a própria realidade socialmente, mesmo as mais prosaicas características do cotidiano. Berger e Luckmann (1967, p. 35) explicam isso afirmando que a vida cotidiana é definida como "realidade interpretada pelos homens e subjetivamente dotada de sentido para eles na medida em que forma um mundo coerente." Schutz (1979) apontou para a ideia de que a interpretação do mundo é feita a partir de categorias oriundas do senso comum e que através delas as pessoas transitam no mundo social, realizando compreensóes intersubjetivas e açóes ordenadas.

Esse mundo social - também chamado de mundo da vida - é o mundo da vida comum, composto pela somatória dos aspectos tomados como naturais para as pessoas que vivem nele, isto é, os pressupostos eficientes, socialmente aprovados que são vistos como fatos que dispensam explicação ou justificativa (SCHUTZ, 1979). Assim, "o mundo da vida cotidiana não somente é tomado como uma realidade certa pelos membros ordinários da sociedade na conduta subjetivamente dotada de sentido que imprimem a suas vidas, mas é um mundo que se origina no pensamento e na ação dos homens comuns, sendo afirmado como real por eles" (BERGER e LUCKMANN, 1967, p 36). 
Existir na vida cotidiana é compartilhar de um mundo intersubjetivo. A interação e comunicação com outros indivíduos são constantes, sendo este o principal indicador de contraste entre as diversas realidades que podem ser concebidas pela consciência. A intersubjetividade permite que haja entre todos os indivíduos a consciência de partilha, no sentido da existência de "uma contínua correspondência entre meus significados e seus significados" (BERGER e LUCKMANN, 1967, p 40).

Essa correspondência contínua está ligada a posse daquilo que Schutz chamou de estoques de conhecimento que, grosso modo, pode ser entendido como "um conhecimento de receitas certas para interpretar o mundo" (1979, p. 83), uma espécie de repertório experiencial sedimentado e vinculado aos nossos costumes que torna os atores sociais capazes de se expressarem, agirem, serem compreendidos e compreenderem outros atores, acontecimentos e coisas de modo habitual, o que garantiria em linguagem schutziana um pensar como sempre e um acordo implícito de perspectivas.

No que consta aquilo que chamei mais acima de "gramática de ser feliz” se pode dizer que ela não foge aquilo que foi apontado nos parágrafos anteriores. Fazendo um paralelo com a ideia de que "pessoas expressam suas emoçóes usualmente nos modos prescritos pela sua cultura" (SHOTT, 1979), que possuem um vocabulário emocional oriundo do mundo da vida, afirmo que o mesmo ocorre com o bem-estar subjetivo. Possuímos uma equivalência entre os significados de felicidade. Eles formam um estoque de conhecimento específico, que utilizamos para ler experiências passadas e presentes, bem como para projetar experiências futuras, interpretando a vida a partir de sentidos particulares de bom e felicidade, os quais estáo ligados a padróes sociais que formam perspectivas comuns, isto é, intersubjetivas.

Sendo um fenômeno social, mas também atrelado ao selfe sua subjetividade, o bem-estar subjetivo está ligado a como as pessoas interagem entre si no processo de construção e desconstrução de configurações reticulares. Há, então, um encontro inevitável entre ideais sociais de felicidade, felicidade individual e os círculos sociais de um determinado indivíduo. Como veremos nas próximas linhas, as configuraçooses reticulares da vida de um ator social são importantes elementos para o seu entendimento individual do que seja bem-estar, pois estáo diretamente ligadas a maneira pela qual sua personalidade e o seu selfse desenvolve.

\section{REDES SOCIAIS E SOCIOLOGIA}

De acordo com Fontes (2012), as redes são fenômenos praticamente naturais e onipresentes que existiriam onde quer que também existam pessoas, inclusive não se limitando apenas a sua agência direta, mas se manifestando também de outras formas como, por exemplo, sistemas elétricos, de distribui- 
ção de água e a rede neural. Falando especificamente das redes sociais, isto é aquelas onde a interação social está implicada diretamente, é possível defini-las da seguinte forma:

A rede social é um grupo de colaboração e ou concorrência entre indivíduos ou entidades que estáo relacionados uns com os outros. Pode ser apresentada como um gráfico, ou um multi-gráfico; cada participante na colaboração ou competição é chamado de ator e é retratado como um nó na teoria dos gráficos. Relaçóes entre os atores são retratadas como links ou laços, quer dirigidos ou sem direçáo, entre os nós correspondentes. Atores podem ser pessoas, organizaçóes ou grupos - qualquer conjunto de entidades relacionadas (ZHANG, 2010, p. 3).

Como se percebe, a teoria de redes preocupa-se com relaçōes, foca-se nos processos dinâmicos dos quais os fenômenos são formados. No que consta mais especificamente a abordagem sociológica, o foco recai sobre um olhar relacional para agência e estrutura, de modo que os dois campos, geralmente postos em oposição, sejam abordados a partir da interação. Apesar de a sociologia reticular ser uma disciplina recente, datando de 1970 aproximadamente, é possível afirmar que a ideia de redes é antiga e está presente na trajetória do pensamento das ciências sociais desde muito cedo, nascendo, inclusive, com um dos clássicos da sociologia. Como deixa claro Fontes (2012), são as ideias do sociólogo alemão George Simmel que serviram como as bases dos desenvolvimentos ulteriores da sociologia das redes. Nas próximas linhas, utilizarei de suas ideias para o desenvolvimento da minha argumentação.

George Simmel possui uma perspectiva sociológica inovadora e bastante diferente daquela sustentada pelos demais pensadores clássicos da disciplina. A sua abordagem, chamada sociologia formal, estabelece a interação como um ponto crucial para o entendimento da sociedade em todo o seu desenvolvimento, sobre isso, Vandenberghe afirma (2005, p. 90-91):

O ângulo de abordagem da sociologia formal [...] define-se pelo fato de que o homem é determinado por viver em interaçáo com seus pares. O que interessa a Simmel é o jogo das interaçóes como substrato vivo do social. [...] as interações são a condição necessária e suficiente da sociedade [...] 'Para um olhar que penetrasse o fundo das coisas, todo fenômeno que parece constituir acima dos indivíduos alguma unidade nova e independente se resolveria em açóes recíprocas entre indivíduos'.

Essa abordagem interacionista metodológica de Simmel nos permite entender que aquilo que nos habituamos a chamar fato social deve ser interpretado como "o resultado das interaçóes cotidianas que ligam os indivíduos" (VANDENBERGHE, 2005, p. 96). Nesta dinâmica, "mesmo o indivíduo ensimesmado em seu ego se reconhece no outro, enquanto componente indis- 
pensável para a construçáo de si mesmo e ao mesmo tempo como ingrediente que cimenta a possibilidade da existência do social” (FONTES, 2015, p. 528).

$\mathrm{Na}$ teoria relacional de Simmel, o que interessa para os nossos propósitos é o conceito de círculo social. Os círculos sociais são observados a partir das interaçóes e estáo relacionados ao que Simmel chama de sociabilidade, designada por ele como a forma lúdica da sociação, sendo esta definida como "a forma (realizada de incontáveis maneiras diferentes) pela qual os indivíduos se agrupam em unidades que satisfazem seus interesses" (SIMMEL 1983, p. 166). É dentro do fenômeno da sociabilidade que o indivíduo se encontra e é nas relações sociáveis que se define como indivíduo (SIMMEL, 1983).

Simmel, partindo do princípio exposto no parágrafo anterior, constrói a ideia de que "A vida cotidiana se estrutura em sociabilidades, pelas quais os indivíduos se localizam em uma geografia social que organiza o viver" (FONTES, 2014, p. 116). Neste bojo, os círculos sociais, grosso modo, poderiam ser entendidos como "espaços" nas quais os indivíduos vivem as dinâmicas interativas das diversas sociabilidades da vida. Eles, a partir de sua configuraçâo moderna, fomentaram individualidades, tornando os indivíduos cada vez mais diferentes uns dos outros, ao mesmo tempo em que apresentam características semelhantes bastante marcantes.

A sociologia simmeliana nos permite entender que o ser humano possui escolhas e experiências únicas. Viver à vida (no sentido de experimentar a existência) é algo particular, contudo essas mesmas escolhas e até mesmo a experiência do viver alocam cada pessoa em campos de pertencimento e reconhecimento onde atuam agregados umas as outras na construção da identidade e do sentido de vida, inclusive aqueles ligados a economia emocional e as perspectivas sobre o bem-estar como será apontado logo mais. Por isso que Simmel afirma que cada indivíduo só tem seu significado em relação aos outros, deixando claro que só fazemos sentido como seres individuais em um contexto relacional (SIMMEL, 1917 apud FONTES, 2012).

Tomando Simmel como ponto de partida, Blau e Schwartz (1997) ressaltam que o cruzamento dos círculos sociais cria uma intricada rede de sobreposição de afiliaçóes sociais. Eles afirmam que um elemento importante no que toca as redes e os círculos sociais que as compóem é a influência do ambiente social nos padróes de relaçóes em uma comunidade, tendo em vista que outras pessoas em seus ambientes determinam as opçóes que as pessoas têm no estabelecimento de suas relaçóes sociais.

Para Blau e Schwartz (1997), a estrutura social, que pode ser definida como as distribuiçóes particulares dos segmentos de uma populaçáo em um dado espaço composto por multidimensionalidades, influenciaria nas configuraçóes reticulares das pessoas no sentido de que haveria a partir da localização do ator em um desses segmentos particulares limitaçôes e possibilidades na sua atuação den- 
tro dos campos de interação. Em outras palavras, o que esses dois autores estão dizendo é que dentro das configuraçóes reticulares de uma sociedade o indivíduo não está totalmente livre no que consta as próprias tomadas de decisão.

$\mathrm{Na}$ opinião desses autores, independentemente da liberdade dos indivíduos, a estrutura dirige os padróes das relaçóes sociais da seguinte forma: limitando as oportunidades de escolha disponíveis e determinando as implicaçóes das escolhas disponíveis no que consta ao relacionamento entre atores e entre os seus grupos de pertencimento. Sobre isso, sintetiza Fontes (2012, p. 98):

Cada pessoa, indiscutivelmente única, mas também existente
por conta de sua relaçáo com o outro, é posicionada cotidia-
namente em múltiplos processos interativos, com posiçôes
relativamente definidas no meio social, com campos de socia-
bilidade estruturados, em parte refletindo desejos e escolhas
pessoais, mas também resultado de padrôes relativamente rí-
gidos existentes na estrutura social que condicionam ou deter-
minam suas trajetórias de sociabilidade.

No que consta, portanto, a representação do mundo é a partir dos vínculos oriundos dos nossos círculos sociais que aprendemos a dar sentido a própria vida. A partir do contato com o outros, tomamos conhecimento do mundo e podemos introjetá-lo como uma realidade que também é nossa. Isso não se dá de maneira neutra, depende da maneira como os círculos sociais se intercalam e se configuram, formatando potencialidades e restriçóes para a agência de um ator social, além disso, essa introjeção também depende da linguagem, pois é ela que permite a objetificação e tipificação de experiências, bem como a organização delas em um todo que faça sentido socialmente (BERGER e LUCKMANN, 1967).

Neste sentido, nos círculos sociais e consequentemente nas configuraçôes reticulares compartilhamos uma subjetividade que é social e que ordena o mundo, dando sentido as nossas relaçóes nos mais diversos aspectos da existência. A partir deles, utilizando da linguagem, construímos uma interpretação da existência que está carregada de valores, impressóes e historicidades particulares. Isso implica que assim como existe uma espécie de estabelecimento de uma forma correta de exercer uma habilidade ou expressar uma opinião também há uma espécie de construção de estados emocionais apropriados e uma maneira legítima de ser feliz, conforme as relaçóes sociais inseridas nos campos de pertencimento definidos pela nossa rede social (SHOTT, 1979).

\section{REDES SOCIAIS E BEM-ESTAR SUBJETIVO}

Afirmei mais acima que somos e experienciamos felicidade a partir de um locus social específico que nos oferece por meio de um vocabulário cultural particular as formas pelas quais é possível manifestar e compartilhar o que 
sentimos. Também disse que essa manifestação é construída pela interação entre pessoas e a correspondência dos seus significados em relação ao mundo.

Tentei expor então que a maneira como experimenta-se a felicidade não é automática ou dependente de uma predeterminação fisiológica e de suas consequências, mas está ligada as complexas relaçóes entre a interpretação do ator e influência social a qual ele é exposto. Portanto, a felicidade, assim como outras emoçóes, seria um artefato cultural. Neste sentido, o que se sente como felicidade e o que se interpreta como felicidade seria guiado pela própria cultura e suas regras emocionais; de modo que diferentes grupos seriam caracterizados por diferentes vocabulários de bem-estar.

Essa pluralidade de noçóes de felicidade está ligada a falta de uma chave universal para descrição, classificação ou avaliação do que se entende como bom (DUARTE, 2010). No entanto, com o desenvolvimento da sociedade ocidental, a dimensão do interior e da intimidade passou por um processo de valorização e devido a isso, mais e mais as pessoas passaram a perceber o bem- estar a partir de referenciais que aludem ao íntimo e ao privado. Em resumo, a felicidade se tornou algo mais pertencente ao campo subjetivo.

Neste mesmo processo, o sentido hodierno de felicidade também se confunde com a ideia de valor, de ideal. Mesmo que experimentada subjetivamente, a felicidade é desejo e esperança de todos, relaciona-se com regimes de bem, culturalmente definidos, dependentes de fontes materiais e imateriais de satisfaçáo (DUARTE, 2010). Esses regimes de bem podem ser acessados a partir das redes sociais, pois elas possuem como característica a possibilidade de alcance aos capitais sociais, seja aquele de aspecto mais íntimo relacionado com a reciprocidade e solidariedade enraizada em vínculos de grande intimidade ou mesmo aquele fomentado pelas formas de associação mais pública. (FONTES, 2011).

Dito isso, nesta parte da reflexão, pretendo esboçar alguns caminhos indicativos mais operacionais de como a influência social, a partir das redes sociais, se relaciona com o bem-estar subjetivo nesses dois âmbitos, isto é, tanto na possibilidade de construção de capitais sociais que permitam o acesso a regimes de bem quanto no que toca a experiência subjetiva de nos sentirmos felizes. Em outras palavras, pretendo apontar caminhos para a elucidação da seguinte questão: como o sentir-se feliz é formado, construído e compartilhado socialmente através de nossas configuraçóes reticulares? Friso que nada aqui é conclusivo, todavia, acredito que posso definir o que está sendo escrito como um a demonstração de proposiçóes relevantes.

\subsection{LAÇOS SOCIAIS, SOCIALIZAÇÃO E COMO APRENDEMOS A NOS SENTIR FELIZES}

Um primeiro caminho possível para apontar as características sociais do bem-estar subjetivo e as configuraçóes reticulares dos atores é o fenô- 
meno da socialização. A socialização é a ampla e consistente introdução de um indivíduo no mundo objetivo de uma sociedade ou de um setor dela. A socialização primária é a primeira socialização que o indivíduo experimenta na infância e em virtude dela torna-se membro da sociedade. A socialização secundária é qualquer processo subsequente que introduz o indivíduo já socializado em novos setores do mundo objetivo de sua sociedade (BERGER e LUCKMANN, 1967, p. 175).

Através da socialização aprendemos diversos aspectos da vida social, aspectos que são inicialmente externos, mas que no decorrer de nossas trajetórias interiorizamos. Esse processo é relacional de maneira dupla: (1) tem como objetivo a compreensão de outros e a apreensáo da realidade do mundo como dotada de sentido; (2) só é possível porque a socialização é feita na interação com outros que são significativos (BERGER e LUCKMANN, 1967).

A partir de nosso lugar em uma rede, somos tanto os que socializam quanto os socializados. Em um primeiro momento, ocupamos o lugar daqueles que aprendem sobre o mundo, mas depois, também somos os responsáveis pelo ensino do mundo para outros atores através das mais diversas instituiçóes. Neste ínterim, nos localizamos enquanto pessoas e localizamos os outros, a partir de coordenadas definidas na história, tomando consciência do que podemos fazer, como podemos fazer e o que devemos esperar da vida (BERGER, 2001).

No fenômeno da socialização apreendemos o mundo, mas não o fazemos sem que juntamente venha com isso uma lente peculiar que o lê e o dota de um sentido particular. Essa lente, o sentido particular do mundo que alguém toma consciência ao ser socializado, é trazida a todos os atores sociais por suas configuraçóes reticulares, o que ocorre porque os nossos círculos sociais desde o nosso nascimento se apresentam como os limites e as possibilidades, abrindo ou restringindo espaços, para o contato e acesso aos diversos sentidos de existência e consequentemente de pertencimento (BLAU e SCHWARTZ, 1997; FONTES, 2012).

Berger e Luckmann (1967) afirmam que na socialização as identidades são definidas paralelamente a apropriação subjetiva do mundo no qual ela é localizada. Aplicando essa colocação, isso significaria dizer que para alguém se tornar, por exemplo, protestante é necessário apreender, com a identidade de protestante, o universo na qual ela faz sentido; o que significaria a inserção dessa pessoa em uma dinâmica de interação e estabelecimento de laços com outros protestantes, os quais ao começarem a fazer parte de seu círculo social a levariam a experienciar uma sociabilidade de aspectos particulares.

O processo de socializaçáo atrelado a esta nova sociabilidade, todavia, não apenas relaciona-se com o aprendizado de como se comporta um protestante ou de como é a interpretação do mundo dessa confissão de fé, pois 
para se tornar algo, e encarnar tal papel como seu, há o aprendizado de uma economia emocional, de reflexão e de conduta que organizam a experiência no mundo nos mais diversos âmbitos, inclusive no emocional. $\mathrm{O}$ fato é que toda essa complexa mudança, que abarca elementos psicológicos e sociais, só foi possível para aquele que se tornou protestante porque na sua configuração social existiu uma organização reticular especifica capaz de apresentar como possibilidade o contato com pessoas dessa expressão de fé.

O mesmo ocorre com o bem-estar subjetivo. Aprendemos o que é ser feliz através dos processos de socialização do qual participamos na construção de nossa identidade. Essa construção identitária está interligada a nossa trajetória enquanto atores sociais, o que, por sua vez, é uma leitura cultural do ciclo biológico que todos experimentam e que é constituído por passagens de status e combinaçóes padronizadas de obrigaçôes e privilégios que carregam cânones de condutas e organização emocional específica (HUGHES, 2005).

No decorrer de nossa carreira, nos inserimos em dinâmicas de interação particulares derivadas dos diversos laços sociais que fomentamos com outros atores, construindo assim nossos círculos sociais e padróes de sociabilidade, nos estruturando enquanto pontos em interação com outros pontos em um tecido social mais amplo e plural, conforme as especificidades da contemporaneidade. A partir dessas configuraçóes reticulares, somos apresentados aos mais inúmeros projetos de felicidade, concepções de bem viver e manifestaçóes particulares deste bem-estar, tudo conforme a bagagem de conhecimento do/sobre o mundo da vida que estáo presentes nos diversos círculos sociais que se interseccionam na caminhada da nossa existência.

Pelas interaçóes em nossos círculos, aprendemos particulares expressóes e representaçóes da felicidade e apreendemos aquela que nos será própria e particular, tomando-a como produto do nosso íntimo, fruto da subjetividade. O processo de apreensão do que é felicidade é paralelo e semelhante aquele pelo qual nos descobrimos enquanto pessoa, pois é dependente do reconhecimento social, daquilo que os outros creem e que paulatinamente tomamos como nosso através do processo de gênese do nosso eu e da descoberta da sociedade enquanto produto relacional.

A felicidade, portanto, só pode ser pensada em termos subjetivos porque fomos socializados e é atribuída socialmente, sustentada socialmente e transformada do mesmo modo. Mesmo que seja entendida por cada um como parte da essência de sua constituição enquanto ser e experimentada não somente a partir de nossa psiquê, mas também das sensações do nosso corpo, a nossa maneira de sentir-se feliz é construída e atribuída socialmente. Nas palavras de Berger (2001, p. 107), "A sociedade determina não só o que fazemos, como também o que somos. Em outras palavras, a localização social não afeta apenas nossa conduta; ela afeta também o nosso ser." 


\subsection{LAÇOS SOCIAIS, PERTENCIMENTOS, RECURSOS, APOIO E BEM-ESTAR SUBJETIVO}

Um segundo ponto onde se pode ver a influência das características das redes sociais em relação ao bem-estar subjetivo são os laços sociais e o consequente sentimento de pertencimento trazido por eles. Sabemos que a sociedade contemporânea é uma realidade complexa e que nela existe uma multiplicidade de pertencimentos disponíveis para os indivíduos. Dentro dos contextos urbanos, permeia no ar uma sensação de lúgubre desordem, apatia e indiferença, mas também um clima fresco de liberdade, diversidade e potência.

A vida urbana é constituída de uma convivência paradoxal de bolsóes de solidão e espaços de intimidade e confidência. Na contemporaneidade, "coexistem, de fato, estruturações de sociabilidades primárias (constituídas de laços fortes) e secundárias (constituídas de laços fracos) cada uma delas gerando um padráo particular de vínculo social" (FONTES, 2012, p. 139). Assim, os laços fortes encerram em si uma realidade de grande intensidade emocional e intimidade, sendo mais comumente encontrados entre familiares e amigos. Enquanto isso, os laços fracos apresentam pouca intimidade e a ausência ou pouca frequência de serviços recíprocos, sendo mais comumente ligado aos contatos fora da alçada privada e emocional.

Os dois tipos de laços são fundamentais para o indivíduo e sua localização naquilo que chamamos antes de mundo da vida, isso ocorre porque é a partir do que experimentamos nas relaçóes constitutivas dos laços que há acesso aos recursos que necessitamos tanto no que consta a aspectos materiais da vida, quanto para aqueles aspectos mais simbólicos e emocionais. Esses arranjos complexos estruturados e estruturantes do cotidiano são o bilhete de passagem tanto para um arcabouço de possibilidades de ação no mundo quanto de representação do mundo aos olhos de quem compartilha os mesmos círculos sociais.

A coexistência entre sociabilidades frágeis e duradouras, portanto, aponta para a realidade de que "as sociedades modernas se ancoram em modelos bastante complexos com articulaçôes entre campos de sociabilidade localizados na esfera pública e privada, naquelas inscritas em campos institucionais amplos (esfera do poder e do mercado) ou restritos (famílias, interaçóes primárias de forma geral)" (FONTES, 2012, p. 140). No nosso contexto, há tanto açóes orientadas racionalmente e que tem como instrumentos e fins o dinheiro e o poder, localizando-se nos espaços de sociabilidade do mercado e do estado, quanto açóes não orientadas pela razão instrumental que são indispensáveis para a manutenção da sociedade, reafirmando laços enquanto produzem uma solidariedade carregada de um conteúdo provindo das relaçóes fomentadas no cotidiano, calcadas na associação voluntária e também em conteúdos sentimentais poderosos (FONTES, 2012). 
Levando isso em consideração, no que consta ao bem-estar subjetivo, é possível afirmar que ambas as dimensóes influenciam nos discursos e representação sobre a felicidade, pois "Passamos do mundo fechado ao universo infinito das chaves da felicidade" (LIPOVETSKY, 2007, p. 337), o que nos expóe, em maior ou menor intensidade, as variadas experiências de satisfação, bem-estar e regimes de bem disponíveis na contemporaneidade conforme nossos círculos sociais se intercruzam (BLAU e SCHWARTZ, 1997).

Todavia, a influência se manifesta também na possibilidade de alcance aos capitais sociais diversos através das nossas configuraçóes reticulares e não apenas na exposição de representações e ideais de felicidade. Os capitais gerados, acessados e gerenciados a partir dos laços sociais abrangem entâo tanto os aspectos mais íntimos da vida, se relacionando com a reciprocidade e solidariedade enraizada em vínculos de grande intimidade, quanto as formas de associação mais pública, as quais ligam-se a outros tipos de recursos como a propagação de informaçóes e os serviços públicos (FONTES, 2011).

No que toca ao primeiro tipo de laço, o capital social pode se manifestar como assistência legal, apoio psicológico, fortalecimento e construção de novos afetos em situações trágicas como o homicídio de um parente (DOMINGUES e DESSEN, 2013) ou mesmo no enfrentamento do câncer, no que consta a minimização do impacto da doença sobre a vida do paciente, manifestando-se através da proteçấo contra sentimentos negativos, experimentação de momentos de diversão e relaxamento, melhora na saúde mental e na sensação de bem-estar (SANTANA, ZANIN e MANIGLIA, 2008). Em contextos menos extremos, mas também delicados, como a terceira idade, recursos como suporte e apoio social, envolvimento em grupos de atividades sociais, pertencimento religioso e residência em contexto rural apresentaram-se como elementos importantes para acréscimo no bem-estar subjetivo dessa população (OLIVEIRA, QUEIROZ e COSTA, 2012). Como se percebe, todas essas atividades requisitam uma sociabilidade mais ou menos ativa onde $o$ idoso se insere como um ator imerso em uma rede composta por laços sociais relativamente coesos.

No que consta aos laços fracos e sua relação com o capital social e o bem-estar subjetivo cita-se seu papel essencial para difusão de informaçóes e também obtenção de um emprego, o que ocorre por meio da criação de pontes mais curtas entre grupos através deste tipo de laço (GRANOVETTER, 1973). Difusão de informação e bem-estar relacionam-se de diversos modos e apenas a título de ilustração é possível exemplificar o caso de atores sociais que compartilham informaçóes de itinerários de cuidado com vizinhos, colegas e trabalho e estranhos em filas, permitindo a propagaçáo de informaçóes sobre práticas terapêuticas alternativas, serviços médicos e práticas tradicionais de cura. No que toca ao trabalho, na atualidade o networking se tornou ferramen- 
ta essencial para a obtenção de um emprego (FERREIRA, 2006) e este tem para maioria da população mundial um caráter positivo que não está apenas ligado ao ganho financeiro, mas também a ideia de sentido de vida, engajamento, convivência e interação, bem como sentimentos positivos (SILVA e TOLFO, 2012; FIDELIS, FERNANDES e TISOTT, 2017).

Todas essas informações servem para chamar a atenção para o relacionamento das redes sociais em suas mais diversas dimensóes com o seguinte aspecto da felicidade:

cerca de metade dos bens cruciais para a felicidade humana não tem preço de mercado nem pode ser adquirida em lojas. Qualquer que seja a sua condição em matéria de dinheiro ou crédito, você não vai encontrar num shopping o amor e a amizade, os prazeres da vida doméstica, a satisfação que vem de cuidar dos entes queridos ou de ajudar um vizinho em dificuldade, a auto-estima proveniente do trabalho bem-feito, a satisfação do "instinto de artífice" comum a todos nós, o reconhecimento, a simpatia e o respeito dos colegas de trabalho e outras pessoas a quem nos associamos; você não encontrará lá proteção contra as ameaças de desrespeito, desprezo, afronta e humilhação. Além disso, ganhar bastante dinheiro para adquirir esses bens que só podem ser obtidos em lojas é um ônus pesado sobre o tempo e a energia disponíveis para obter e usufruir de bens não-comerciais e não negociáveis como o que citamos acima. Pode facilmente ocorrer, e frequentemente ocorre, de as perdas excederem os ganhos e de a capacidade de renda ampliada para gerar felicidade ser superada pela infelicidade causada pela redução do acesso aos bens que "o dinheiro não pode comprar". (BAUMAN, 2009, p. 12)

A proposição que coloco aqui, portanto, é a da ideia de que a associação entre pessoas e a construção de laços sociais são geradores do bem-estar subjetivo, pois permitem a experimentação de bens que os recursos mercantis são impossíveis de acessar através de sua lógica. Apesar de ser um fato que laços sociais e associaçôes de pessoas podem também gerar constrangimentos e violência, como no caso do estigma, um fenômeno que é interacional em essência, também é um fato que a desestigmatização, por exemplo, passa pela multiplicação e/ou fortalecimento de laços sociais (HISHAW, 2009), pois o apoio social acessado via laços fortes fomenta resiliência (FONTES, 2012).

O caso de pessoas com transtorno psíquico é emblemático. Elas enfrentam o retraimento da vida social e entram em um ciclo de morte social calcado no isolamento, exclusão, culpa e vergonha. No entanto, apesar dessa realidade marcada pelo sofrimento, é possível que essas pessoas por meio de suas configuraçóes reticulares extraiam uma série de recursos para além daqueles que o dinheiro pode comprar, recebendo apoio e encontrando nas relaçóes sociais entusiasmo, alegria, empolgação e partilha. Por mais que isso não seja algo fá- 
cil ou mesmo frequente de ocorrer quando se fala de pessoas com transtornos mentais, é um indicativo de que vidas em sofrimento podem experimentar sentimentos ligados ao bem-estar quando protagonizam interaçóes embebidas de contatos positivos (NASCIMENTO, 2015).

$\mathrm{O}$ mesmo efeito ocorre em atores que não apresentam um quadro de sofrimento psíquico. Sentimentos positivos emanam das boas relaçóes, dos arranjos sociativos que tais atores protagonizam e são ingredientes fundamentais do seu bem viver. A aceitação social é uma prioridade de qualquer indivíduo e os laços sociais são uma fonte importante para a obtenção tanto da aceitação social quanto da sensaçáo subjetiva de ser aceito. Sentir-se parte de algo, pertencente a um lugar tem um impacto no bem-estar individual na medida em que permite a construção de uma consciência do próprio ser enquanto ser em pertencimento de um todo para além de si mesmo, além disso, implica uma postura mais ativa na qual o associativismo e o protagonismo público podem se manifestar como consequência do sentir-se bem (NASCIMENTO, 2015).

Se, no primeiro ponto, eu explorei como as redes sociais de um indivíduo moldam a maneira como ele sente e percebe a felicidade a partir de sua socialização, neste segundo ponto a atenção recai para a relação dos laços sociais com o acesso aos mais diversos recursos promotores de bem-estar. Por ser esse conjunto de conteúdos encontrado nas relaçóes sociais de uma rede, o capital social envolve tanto o âmbito mais individual quanto aquele coletivo, permitindo a alocação e utilização de diversos recursos que não poderiam ser acessados de outra forma. Muito embora a distribuição desse tipo de capital não seja igualitária, dependendo de diversos fatores tais como a posição do ator na rede e também sua identidade social ou prestígio na coletividade, sua posse permite a realização dos mais diversos objetivos que interseccionam recursos simbólicos e materiais através da organização dos laços de um determinado ator.

Essa realização de objetivos tem um impacto bastante substancial naquilo que entendemos como felicidade e bem-estar não somente porque na contemporaneidade a felicidade nos é trazida como um ideal e um valor, mas também porque a mobilizaçáo de recursos pelo uso do nosso capital social traz consigo a sensação de êxito e sucesso, os quais se constituem como elementos contributos para o bem-estar subjetivo, conforme é entendido atualmente (FERRAZ, TAVARES e ZIBERMAN, 2007).Neste sentido, as redes sociais se tornam cenários e concebedoras de estados de felicidade por dois motivos importantes: primeiro, a partir das interaçóes vivenciadas nelas nós experimentamos e construímos nossos referenciais de bem-estar; segundo, elas também se apresentam como instrumentos de busca de felicidade na medida em que nessas mesmas interações nós encontramos os recursos necessários para obtermos os ingredientes sociais do ser feliz. 


\section{CONSIDERAÇÓESS FINAIS}

A intenção do artigo foi abordar a questão da felicidade ou bem-estar subjetivo por uma ótica sociológica. $\mathrm{O}$ texto teve por objetivo apresentar argumentos propositivos que apontassem como fenômeno que é capturado como algo exclusivamente, ou melhor, predominantemente subjetivo, e, por isso da alçada da psicologia, possui uma série de características que são sociais. Sentir-se feliz é de fato algo do âmbito das emoçôes e do interior do nosso ser, mas isso não significa que não esteja embebecido pelo social, muito pelo contrário, aquilo que nos é mais individual só pode ser assim porque temos relação com outros seres humanos e compartilhamos com eles a capacidade de individuação. Ser feliz é algo que os indivíduos experimentam a partir das orientações advindas de seus horizontes sociais.

Contudo, para nós não bastava mostrar que a felicidade é um objeto sociológico legítimo e que possui características sociais, buscamos demonstrar que, para além disso, o bem-estar subjetivo envolve aspectos relacionais manifestos nas possibilidades e restrições que são apresentadas aos atores por suas configuraçóes reticulares. Por ser um ensaio teórico, buscou-se construir um argumento embasado em um bojo teórico que me permitisse ao menos levantar de maneira coerente a hipótese de que as redes sociais influenciam na subjetivação da felicidade, na manifestação do bem-estar e também na construção dele. $\mathrm{Na}$ empreitada que é a jornada para a felicidade, nenhum indivíduo se vê sozinho, mas está mergulhado em um mar de interaçóes constantemente tecidas e que implicam nele estratégias e entendimentos sobre como e o que é ser feliz. Dito isso, as linhas escritas não podem chegar a conclusóes, não pode haver a pretensão de uma resposta conclusiva neste ensaio, porém deve haver um ponto final e que este seja um conjunto de inquietaçóes propositantes para um tema instigante.

Primeiramente, o que se pode sugerir como esboços de respostas é que: (2) as pessoas inseridas em nossas redes sociais são responsáveis por nosso processo de socialização e isso significa também, mas não só isso, a apresentação de uma concepção particular do mundo, inclusive influenciando nas representaçôes de fenômenos como a felicidade, o que é acompanhado por um aprendizado de uma economia emocional particular. Portanto, nossa construção subjetiva de entendimentos sobre o bem-estar é derivada do mesmo processo em que nos reconhecemos como pessoa e descobrimos a sociedade e se constitui como um fenômeno relacional que remete ao caráter intersubjetivo de nossa mente. (3) As redes sociais oportunizam os atores a se inserirem em grupos que propiciam interação e a associação de cunho positivo, fomentando sentimentos de bem-estar e potencialmente proteçáo contra as ameaças de desrespeito, desprezo, afronta e humilhação de modo que apresentam para 
ele uma realidade de pertencimento e uma qualidade de relação social para além da lógica instrumental. (4) As redes sociais também são repositórios de capital social que pode ser usado para a obtenção de recursos que agreguem para os atores importantes contribuiçóes para o bem-estar subjetivo, isto pode ser materializado de diversos modos desde conforto em momentos difíceis até apoio financeiro, jurídico e também na participação conjunta em atividades recreativas que impliquem em sentimentos positivos. (5) Finalmente, não só os recursos gerados, mas a própria realização dos planos e projetos, independente do capital social acessado, influenciariam no bem-estar subjetivo de um indivíduo na medida em que emergiriam disso sensações de êxito e sucesso.

Por fim, para não somente ficar na proposição de respostas teóricas e também por entender que um tema instigante necessita de encaminhamentos para pesquisa, gostaria de propor os seguintes insights para uma investigação empírica: (1) investigaçóes focadas na socialização e sua relação com os círculos sociais na construção dos sentidos intersubjetivos de felicidade. Neste âmbito, seria possível, por exemplo, pensar como uma determinada socialização religiosa impacta na formação de atores sociais uma representação social da felicidade particular; também seria igualmente válido e relevante estudos que se propusessem compreender como se dá a construção do bem-estar subjetivo na juventude, talvez, relacionando-o com questôes como o consumismo. (2) Estudos empíricos sobre associativismo, pertencimento e felicidade. Aqui, as pesquisas poderiam focar nos laços sociais e seu papel na formação dos grupos, das identidades sociais, na economia emocional relativa a eles e seus impactos no bem-estar subjetivo, se propondo a elucidar de forma empírica como grupos sociais, formados através de nossos círculos, nos auxiliam a experienciar sentimentos ligados a felicidade. (3) Como último ponto, sugerimos também a construção de sociogramas que deem conta de mapear os recursos relativos ao bem-estar e o caminho percorrido pelos indivíduos até eles. Nessa perspectiva, o intuito poderia ser demonstrar graficamente as conexôes reticulares mais relevantes na captaçáo dos recursos não mercantis, tais como o apoio social.

\section{REFERÊNCIAS}

BAUMAN, Zygmunt. A Arte da Vida. 1 $^{\text {a }}$ ed. Rio de Janeiro: Jorge Zahar Ed., 2009

BERGER, Peter L., LUCKMANN, Thomas. A Construçáo Social da Realidade: tratado de sociologia do conhecimento. Editora Vozes: Petrópolis, 1967.

BERGER, Peter. Perspectivas Sociológicas: uma visão humanista. Florianópolis: Vozes, 2001. 
BLAU, Peter Michael; SCHWARTZ, Joseph E.. Crosscutting Social Circles: testing a macrostructual theory of intergroup relations. Orlando: Academic Press, 1997.

DOMINGUES, Daniela Fontoura; DESSEN, Maria Auxiliadora. Reorganização Familiar e Rede Social de Apoio Pós-homicídio Juvenil. Psicologia: Teoria e Pesquisa, Brasília, v. 28, n. 2, p.141-148, abr./jun. 2013.

DUARTE, Luiz Fernando Dias. Muitas Felicidades! Diferentes regimes do bem nas experiências da vida. In: FREIRE FILHO, João (Org.). Ser Feliz Hoje: Reflexóes sobre o imperativo da felicidade. Rio de Janeiro: Fgv Editora, 2010. p. 239-255.

FERRAZ, Renata Barboza; TAVARES, Hermano; ZILBERMAN, Monica L.. Felicidade: uma revisão. Revista de Psicologia Clínica, São Paulo, v. 5, n. 34, p. 234-242, jun. 2007.

FERREIRA, Márcia Crespo. A Importância das Redes Sociais e o Gerenciamento de Carreira para a Inserção no Mercado de Trabalho. Pretexto, Belo Horizonte, v. 7, n. 2, p. 21-38, jun./dez. 2006.

FIDELIS, Andréa Cristina Fermiano; FERNANDES, Antonio Jorge; TISOTT, Priscila Bresolin. A Relaçáo entre Felicidade e Trabalho: Um Estudo Exploratório com Profissionais Ativos e Aposentados. Psi Unisc, Santa Cruz do Sul, v. 1, n. 2, p. 29-32, dez. 2017.

FONTES, Breno Souto Maior. Tecendo Redes, Suportando o Sofrimento: sobre os círculos sociais da loucura. Sociologias, Porto Alegre, v. 16, n. 37, p. 112-143, nov. 2015.

FONTES, Breno Augusto Souto Maior. Redes sociais e Poder Local. Recife: Ed. Universitária UFPE, 2012.

FONTES, Breno Souto Maior. La contribuciónde Simmel a la sociología reticular. Estudios Sociológicos, México, v. 32, n. 99, p. 527-552, Set. 2014. FONTES, Breno Augusto Souto Maior. Redes, Práticas Associativas e Poder Local. Curitiba: Editora Appris, 2011.

GRANOVETTER, Mark. The Strength of Week Ties. American Journal Of Sociology, Chicago, v. 78, n. 8, p.1360-1380, mai. 1973.

HINSHAW, Stephen P. The mark of shame: Stigma of mental illness and an agenda for change. Oxford University Press, 2009.

HUGHES, Everett C. Ciclos, pontos de inflexão e carreiras. Teoria e Pesquisa. n. 46, p. 163- 173, 2005. 
JOAS, Hans; KNÖBL, Wolfgang. Social Theory: Twenty Introductory Lectures. New York: Cambridge University Press, 2013.

LIPOVETSKY, Gilles. Felicidade Paradoxal: Ensaio sobre a sociedade do hiperconsumo. São Paulo: Companhia das Letras, 2007.

MACMAHON, Darrin M., Felicidade: uma história. $1^{\text {a }}$ ed. São Paulo: Globo, 2006.

NASCIMENTO, Álvaro Botelho de Melo. Estigma, sociabilidade e práticas terapêuticas: a terapia comunitária como âncora e alívio do Transtorno Mental. 2015. Disponível em: <http://repositorio.ufpe.br/handle/123456789/13983>. Acesso em: 20 jul. 2016.

OLIVEIRA, S.F.; QUEIROZ, M.I.N.; COSTA, M.L.A. Bem-estar subjetivo na terceira idade. Motricidade, Vila Real, v. 8, n. 2, p. 1038-1047, 2012.

SANTANA, Jeanny Joana Rodrigues Alves de; ZANIN, Carla Rodrigues; MANIGLIA, José Victor. Pacientes com câncer: enfrentamento, rede social e apoio social. Paidéia, Ribeirão Preto, v. 40, n. 18, p.371-384, ago. 2008.

SHOTT, Susan. Emotion and Social Life: A Symbolic Interactionist Analysis. American Journal Of Sociology, Chicago, v. 84, n. 6, p.1317-1334, maio 1979.

SILVA, Narbal; TOLFO, Suzana da Rosa. Trabalho Significativo e Felicidade Humana: Explorando Aproximaçóes. Revista Psicologia: Organizaçóes e Trabalho, Brasília, v. 3, n. 12, p.341-351, set./dez. 2012.

SIMMEL, Georg. Georg Simmel: sociologia. São Paulo: Editora Ática, 1983. VANDENBERGHE, Frédéric. As Sociologias de George Simmel. Bauru: Edusc; Belém: EDUPFA, 2005.

ZHANG, Mingxin. Social network analysis: History, concepts, and research. In: Handbook of social network technologies and applications. Springer, Boston, MA, 2010. p. 3-21. 